\title{
The Effect of Hydrogen Peroxide on a Chemical Oscillating Reaction
}

\author{
Nanqin Gan, Ruxiu CAI, and Zhixin LIN \\ Chemistry Department, Wuhan University, Wuhan, 430072 P. R. C.
}

\begin{abstract}
This paper studies the perturbation of hydrogen peroxide in an oscillating chemical system involving the Mn(II)-catalyzed reaction between diacetone and potassium bromate in an acidic medium in a closed system (beaker) and an open system (continuous-flow-stirred tank reactor (CSTR)). The best reaction conditions and reactant concentrations are reported. The presence of $\mathrm{H}_{2} \mathrm{O}_{2}$ inhibits the oscillation and results in a longer oscillating periods. Potential and cyclic voltammetry were used to track the change of the reaction intermediates. The possible mechanism of the effect of hydrogen peroxide is discussed.
\end{abstract}

(Received April 3, 2000; Accepted July 31, 2000)

\section{Introduction}

Hydrogen peroxide is a very important intermediate in clinical biochemistry ${ }^{1,2}$ and environmental work. ${ }^{3,4}$ Hydrogen peroxide is produced in stoichiometric amounts during the oxidation of substrates of clinical interest by dissolved oxygen in the presence of the corresponding oxidase enzyme. Methods such as titrimetry, UV-vis spectrophotometry, and electrochemistry have been developed for the study of hydrogen peroxide. ${ }^{5-7}$ Usually, they are operated in neutral or weak alkaline media. ${ }^{8}$ However, in some cases, such as in the fermentation industry, the food industry, and environmental analysis, ${ }^{6,9}$ samples containing $\mathrm{H}_{2} \mathrm{O}_{2}$ exhibit acidity. Therefore, the study of hydrogen peroxide directly in an acidic medium is practically important and expedient.

Oscillating chemical systems are always complex and involve a large number of chemical species, which can be categorized as reactants, products, and intermediates that interact via unusual mechanisms. ${ }^{10,11}$ The most widely known and studied oscillating chemical systems are those based on the Belousov-Zhabotinskii (B-Z) and Bray-Liebhafsky (B-L) reactions. Here, the FKN mechanism proposed by Field, Koros and Noyed has been widely accepted. ${ }^{12,13}$ In past years, many workers have focused on the studies of theoretical and experimental chemical kinetics. Recently, the oscillating reaction has also been of interest to a few analytical chemists who use oscillating period, amplitude or induction time as the analytical parameter based on various oscillating reactions. ${ }^{14,15}$ Advantages of the application of non-linear chemical systems under far from equilibrium conditions in analysis are obvious, e.g., the methodological approach termed the analyte pulse perturbation (APP) technique. ${ }^{16}$

In this paper, we report two experimental setups (one is beaker, the other is CSTR) to study the effect of hydrogen peroxide in diacetone- $\mathrm{BrO}_{3}{ }^{-}-\mathrm{Mn}(\mathrm{II})-\mathrm{H}_{2} \mathrm{SO}_{4}$ oscillating chemical system which is an acidic medium. The influences of

† To whom correspondence should be addressed.

E-mail:dlxfxc@whu.edu.cn temperature, the concentrations of reactants, and flow rate on the system were investigated. Interaction of hydrogen peroxide with this system shows that it can inhibit the reaction and lengthen the oscillating period. Electrode potential and cyclic voltammetry were used to track the change of the reaction intermediates. A possible mechanism of the effect of hydrogen peroxide is proposed.

\section{Experimental}

\section{Reagents}

All chemicals were of analytical reagent grade. Solutions of diacetone, $\mathrm{KBrO}_{3}$ and $\mathrm{MnSO}_{4}$ were separately prepared in 1.0 mol L ${ }^{-1}$ sulfuric acid. Hydrogen peroxide was standardized by titration with secondary standard $\mathrm{KMnO}_{4}$, and the concentration is $10.64 \mathrm{~mol} \mathrm{~L}^{-1}$. The concentration of hydrogen peroxide was allocated according to the demands of the experiment. Doubly distilled water was used throughout.

\section{Apparatus}

The experimental set-up used to implement the oscillating reaction consisted of a glass reaction vessel furnished with a thermostated jacket connected to a TB-85 thermostat (Japan) and a type HJ-3 magnetic stirrer (Hangzhou Electric Instrument). The indicator electrode was a platinum electrode and the reference electrode was a type 217 saturated calomel electrode (Nanjin Apparatus and Instrumental Facility) with a laboratory-constructed agar salt bridge containing $10 \% \mathrm{KNO}_{3}$. A type $3056 \mathrm{X}-\mathrm{Y}$ recorder (Sichuan Instrument and Meter Factory) was used to record the potential changes. The peristaltic pump (Masterflex, Cole-Parmer Instrument) was used to deliver the reactant streams at a constant overall flow rate. The sample injection valve (LZ-1020 Shenyang Film Viewfinder Factory) was used to inject the samples.

A PAR 175 universal programmer coupled with a PAR 173 potentiostat (EG\&G PAR, Princeton, NJ) and a Model WX4401 $\mathrm{X}-\mathrm{Y}$ recorder (Watanabe, Tokyo) were used for cyclic voltammetric measurements. The electrode system used was a glassy carbon working electrode (Jiangshu Electroanalytical 

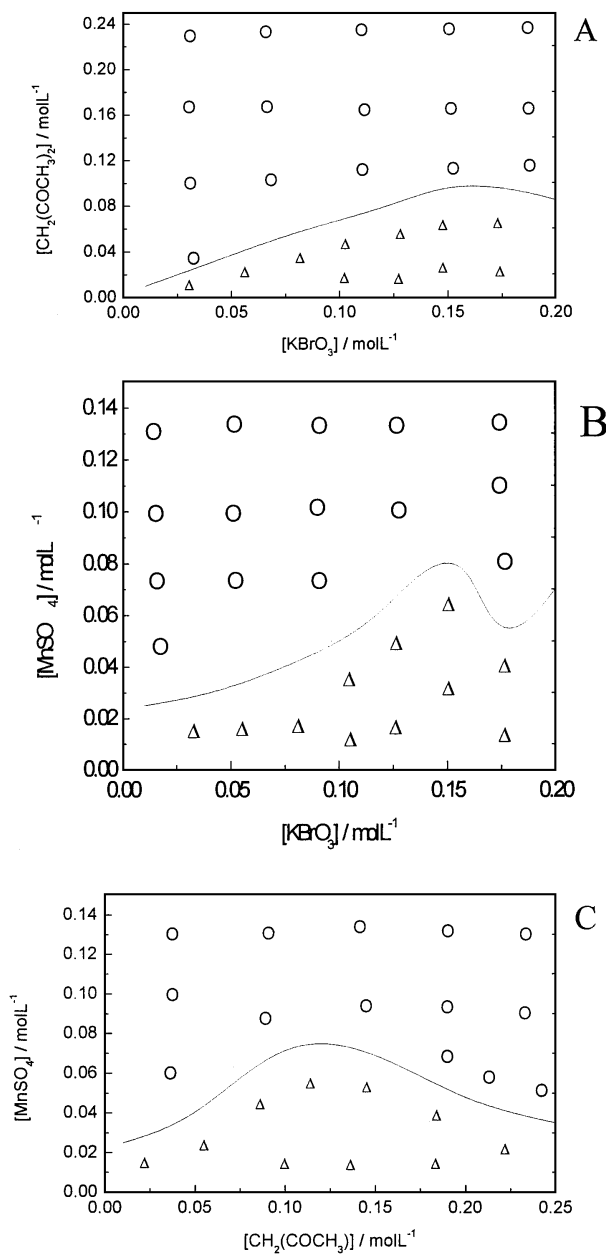

Fig. 1 Phase diagram of the system diacetone- $\mathrm{BrO}_{3}{ }^{-}-\mathrm{Mn}$ (II)$\mathrm{H}_{2} \mathrm{SO}_{4}$. (A) $\left[\mathrm{MnSO}_{4}\right]=0.08 \mathrm{~mol} \mathrm{~L}^{-1}$, (B) $\left[\mathrm{KBrO}_{3}\right]_{0}=0.15 \mathrm{~mol} \mathrm{~L}^{-1}$, (C) $\left[\mathrm{CH}_{2}\left(\mathrm{COCH}_{3}\right)_{2}\right]_{0}=0.1 \mathrm{~mol} \mathrm{~L}^{-1}$. $\left[\mathrm{H}_{2} \mathrm{SO}_{4}\right]_{0}=1.0 \mathrm{~mol} \mathrm{~L}-1$; flow rate $=7.75 \times 10^{-5} \mathrm{~L} / \mathrm{s} . \Delta$, stable states; $\mathrm{O}$, oscillating.

Instrumental Factory), a platimun counter electrode and a reference saturated calomel electrode as above. The reference electrode was connected to a PAR 178 electrometer.

\section{Procedure}

The temperature was maintained at $303 \pm 0.20 \mathrm{~K}$ and the total reaction volume was $20 \mathrm{~mL}$. The oscillating reactions were effected in a water-jacketed glass vessel with a magnetic stirrer bar.

In the beaker system, to the reaction vessel were added first 5 $\mathrm{ml}$ of $0.1 \mathrm{~mol} \mathrm{~L}^{-1}$ diacetone and then, $5 \mathrm{ml}$ of $0.08 \mathrm{~mol} \mathrm{~L}^{-1}$ $\mathrm{MnSO}_{4}$ with magnetic stirring. The oscillating reaction was started by adding $10 \mathrm{ml}$ of $0.15 \mathrm{~mol} \mathrm{~L}^{-1} \mathrm{KBrO}_{3}$ and, without delay, the potentiometric oscillating curves were recorded.

In CSTR, a peristaltic pump delivered the reactant streams (0.08 $\mathrm{mol} \mathrm{L}^{-1} \mathrm{MnSO}_{4}, 0.15 \mathrm{~mol} \mathrm{~L}^{-1} \mathrm{KBrO}_{3}$ and $0.1 \mathrm{~mol} \mathrm{~L}^{-1}$ diacetone in $1.0 \mathrm{~mol} \mathrm{~L}^{-1} \mathrm{H}_{2} \mathrm{SO}_{4}$ ) at a constant overall flow rate of $7.75 \times 10^{-5} \mathrm{~L} / \mathrm{s}$. When the reactants were mixed, the system began the oscillating reaction immediately. After the oscillating amplitude and period had stabilized, variable concentrations of hydrogen peroxide were sequentially injected with the sample injection valve. After the system regained its stable oscillating mode, a new perturbation can be taken.

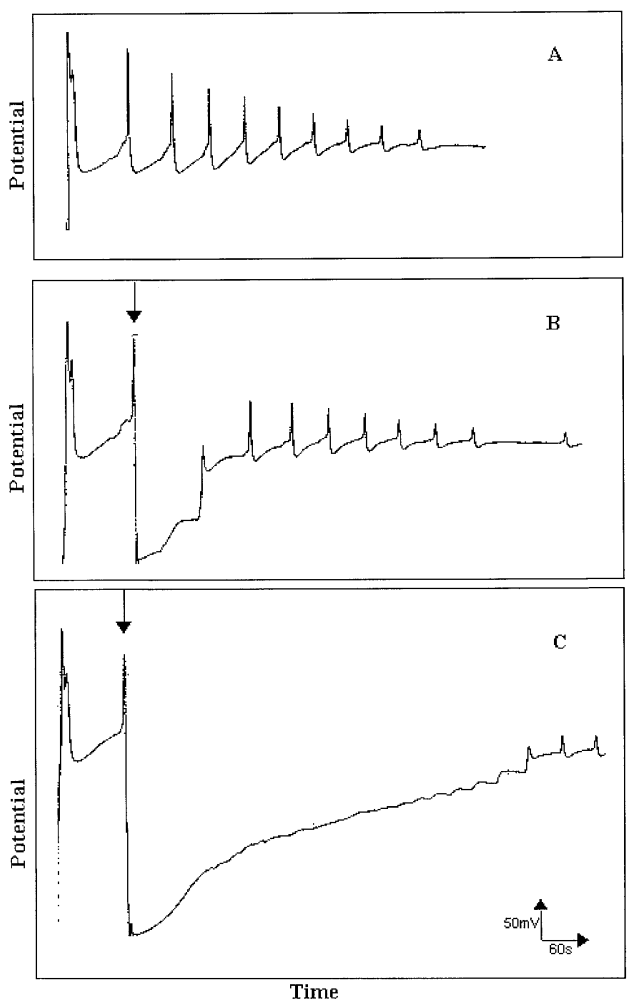

Fig. 2 Typical profiles for the diacetone- $\mathrm{BrO}_{3}{ }^{-}-\mathrm{Mn}(\mathrm{II})-\mathrm{H}_{2} \mathrm{SO}_{4}$ oscillating system in the absence and presence of perturbations in beaker. (A) $0 \mathrm{~mol} \mathrm{~L}^{-1}$ hydrogen peroxide; (B) $4 \times 10^{-6} \mathrm{~mol} \mathrm{~L}^{-1}$ hydrogen peroxide; (C) $4 \times 10^{-5} \mathrm{~mol} \mathrm{~L}^{-1}$ hydrogen peroxide. The arrowhead indicates hydrogen peroxide. Conditions: $1.0 \mathrm{~mol} \mathrm{~L}^{-1}$ $\mathrm{H}_{2} \mathrm{SO}_{4}, 0.08 \mathrm{~mol} \mathrm{~L}^{-1} \mathrm{MnSO}_{4}, 0.15 \mathrm{~mol} \mathrm{~L}^{-1} \mathrm{KBrO}_{3}$, and $0.1 \mathrm{~mol} \mathrm{~L}^{-1}$ diacetone, temperature $303 \mathrm{~K}$.

\section{Results and Discussion}

\section{Typical oscillatory behavior}

In the beaker system, a yellowish-green to white oscillating began quickly with the addition of $\mathrm{KBrO}_{3}$, which was a damped oscillating. It can be maintained 10-30 min. On the interaction with this oscillating system, hydrogen peroxide inhibited the oscillating and caused changes in the oscillating period and the system cannot return to the original oscillating state. In CSTR, the system showed an oscillating with the color changes, that is yellowish-green, pink and white. It can be maintained at least $10 \mathrm{~h}$. With the addition of hydrogen peroxide, the oscillatory period changed and after the perturbation, the system gradually returned to the stable oscillating.

\section{Influence of variables on the oscillation}

Effect of temperature. Temperature has a strong influence on the oscillating system, an increase from 293 to $318 \mathrm{~K}$ dramatically decreased the oscillation period when keeping the concentration of all reactors. The figure of $\ln \left(1 / t_{\mathrm{p}}\right)$ and $\ln \left(1 / t_{\mathrm{p}}{ }^{\prime}\right)$ against $1 / T$ conforms to the Arrhenius linear relationship, $\ln \left(1 / t_{\mathrm{p}}\right)=-E_{\mathrm{p}} / R T$ $+C ; \ln \left(1 / t_{\mathrm{p}}{ }^{\prime}\right)=-E_{\mathrm{p}}{ }^{\prime} / R T+C\left(E_{\mathrm{p}}=f\left(E_{\mathrm{a}}\right), E_{\mathrm{p}}{ }^{\prime}=f^{\prime}\left(E_{\mathrm{a}}\right), E_{\mathrm{a}}\right.$ (activation energy), $T$ (temperature), $C$ (constant)), we can get a good linear relationship between $\ln \left(1 / t_{\mathrm{p}}\right), \ln \left(1 / t_{\mathrm{p}}{ }^{\prime}\right)$ and $1 / T$, and get an apparent activity parameter $\left(E_{\mathrm{p}}=100.68 \mathrm{~kJ} \mathrm{~mol}^{-1}\right)$ of the oscillatory period without hydrogen peroxide and apparent activity parameter $\left(E_{\mathrm{p}}{ }^{\prime}=109.70 \mathrm{~kJ} \mathrm{~mol}^{-1}\right)$ of the oscillatory period with 


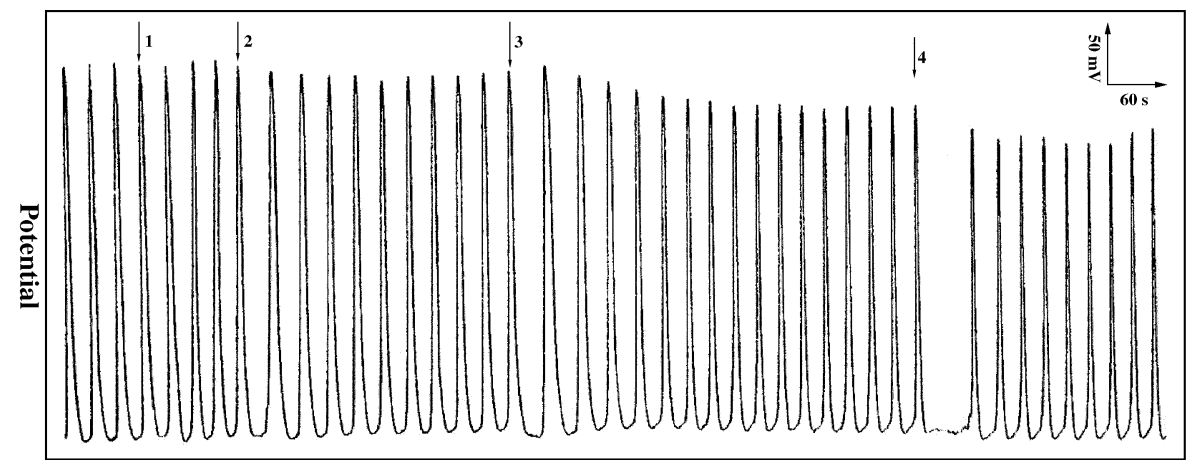

Time

Fig. 3 Typical profiles for the diacetone- $\mathrm{BrO}_{3}{ }^{-} \mathrm{Mn}(\mathrm{II})-\mathrm{H}_{2} \mathrm{SO}_{4}$ oscillating system in CSTR. Arrowheads1 and 2 indicate the time at which $6.20 \times 10^{-7} \mathrm{~mol} \mathrm{~L}^{-1}$, and $1.15 \times 10^{-6} \mathrm{~mol} \mathrm{~L}^{-1}$ hydrogen peroxide was injected respectively. Other conditions as the same as in Fig. 2.

hydrogen peroxide. If one compares the two aspects, when hydrogen peroxide is added to the system, the apparent activity parameter increases, which means that hydrogen peroxide is the stronger inhibitor to the oscillating reaction.

Effect of reaction components. The influence of the $\mathrm{H}_{2} \mathrm{SO}_{4}$ was investigated over the range $0.5-2.5 \mathrm{~mol} \mathrm{~L}^{-1}$. When the $\mathrm{H}_{2} \mathrm{SO}_{4}$ concentration was increased, the oscillation period decreased strongly.

In the absence of $\mathrm{MnSO}_{4}$, no oscillation phenomenon was observed, and after a long period, the solution became yellowgreen in color. This indicated that the activated energy $\left(E_{\mathrm{a}}\right)$ of the reaction was high and that the addition of $\mathrm{Mn}$ (II) can catalyze the reaction. Effect of $\mathrm{MnSO}_{4}$ concentration was studied over the range from 0.005 to $0.225 \mathrm{~mol} \mathrm{~L}^{-1}$. The oscillating period and amplitude were found to increase with increasing $\mathrm{Mn}(\mathrm{II})$ concentration.

In the absence of $\mathrm{KBrO}_{3}$, no reaction generated in the solution of $\mathrm{MnSO}_{4}$ and diacetone; the adding of $\mathrm{KBrO}_{3}$ resulted in an immediate change of the solution color into yellow-green. Raising the concentration of $\mathrm{KBrO}_{3}\left(0.01-0.20 \mathrm{~mol} \mathrm{~L}^{-1}\right)$ caused the oscillating period to decrease without altering the oscillating amplitude. The concentration of $\mathrm{KBrO}_{3}$ below $0.01 \mathrm{~mol} \mathrm{~L}^{-1}$ was not enough to induce the oscillating reaction.

Lacking diacetone made the solution take on the orange color, no oscillating reaction took place and the potential was relatively high. Adding diacetone made the solution take a yellow-green color, in the meantime, the potential of the system began to decrease and the system started to oscillate. As the concentration of diacetone increased from $0.005 \mathrm{~mol} \mathrm{~L}^{-1}$ to 0.25 mol $\mathrm{L}^{-1}$, the oscillating period increased slowly while the amplitude has a slight decrease and the yellow-green color of the intermediate became intense.

Figure 1 shows the phase diagram of the system, when two reaction components are changed, while the other conditions are not changed, this phase diagram can show the stable states and the oscillating states.

Effect of flow rate. Finally, the effect of the overall reactant flow-rate fed on the CSTR was studied; this variable influence fed on the CSTR was studied; this variable influenced the ease with which the stable oscillating was regained after each perturbation and hence, the reproducibility and the system resistance to the perturbations. Decreasing the ratio of the system volume $(20 \mathrm{~mL}$ to the overall reactant), flow-rate, which was changed between $1.05 \times 10^{-5} \mathrm{~L} \mathrm{~s}^{-1}$ and $4.00 \times 10^{-4} \mathrm{~L} \mathrm{~s}^{-1}$, was found to result in an increasingly reproducible response to the hydrogen peroxide perturbation. A unity ratio (i.e. an overall reactant) flow-rate of $7.75 \times 10^{-5} \mathrm{~L} \mathrm{~s}^{-1}$ was adopted as optimal.

\section{Effect of hydrogen peroxide on the oscillating system}

The oscillating system was perturbed with various concentrations of hydrogen peroxide under the above-described conditions. When hydrogen peroxide is added to the solution, the yellow color deepened immediately, and eventually become almost colorless, the oscillation period increases and the oscillation amplitude decreases both in beaker (Fig. 2) and CSTR (Fig. 3).

In CSTR system, the change of the oscillating amplitude is very small, while in the batch system, the change is bigger. That is because in the batch system, the addition of $\mathrm{H}_{2} \mathrm{O}_{2}$ can affect the whole system and no fresh reagent is supplied, but in CSTR system, the reaction components are entered constantly, and the resultant is discharged constantly. So the closed system (beaker) must come to equilibrium, and the equilibrium state is stable and unique, so any oscillations must necessarily be transient. The CSTR maintains the system far from equilibrium and is allowed to give a stable oscillation for at least $10 \mathrm{~h}$, and the concentrations of the reaction components are much wider than ever. During such time, as many perturbations as required could be applied without stopping the oscillation. Based on the time needed for the system to recover after each perturbation, the throughput can be estimated to be $6-9$ samples every hour, which is much better than the beaker system.

Mechanism of the action of hydrogen peroxide on the oscillating system

According to the experimental phenomenon, the cyclic voltammograms of the system, the basic idea of FKN mechanism, and the possible mechanism of the diacetone- $\mathrm{BrO}_{3}^{-1}-\mathrm{Mn}(\mathrm{II})$ $\mathrm{H}_{2} \mathrm{SO}_{4}$ oscillating chemical system we have studied in past work, ${ }^{17}$ we can conclude that the system might involve four important reaction courses.

(I) $\mathrm{BrO}_{3}^{-}+4 \mathrm{Br}^{-}+5 \mathrm{H}^{+} \rightarrow 2 \mathrm{Br}_{2}+\mathrm{HOBr}+2 \mathrm{H}_{2} \mathrm{O}$

(II) $\mathrm{BrO}_{3}^{-}+5 \mathrm{CH}_{2}\left(\mathrm{COCH}_{3}\right)_{2}+2 \mathrm{Br}_{2}+5 \mathrm{H}^{+} \rightarrow$ $5 \mathrm{BrCH}\left(\mathrm{COCH}_{3}\right)_{2}+3 \mathrm{H}_{2} \mathrm{O}$

(III) $\mathrm{BrO}_{3}^{-}+4 \mathrm{Mn}^{2+}+5 \mathrm{H}^{+} \rightarrow \mathrm{HOBr}+4 \mathrm{Mn}^{3+}+2 \mathrm{H}_{2} \mathrm{O}$

(IV) $2 \mathrm{Mn}^{3+}+\mathrm{HOBr}+2 \mathrm{BrCH}\left(\mathrm{COCH}_{3}\right)_{2}+\mathrm{Br}_{2}+5 \mathrm{H}_{2} \mathrm{O} \rightarrow$ $4 \mathrm{Br}^{-}+2 \mathrm{Mn}^{2+}+2 \mathrm{CH}_{3} \mathrm{COOH}+\mathrm{CH}_{3} \mathrm{CHO}+\mathrm{HCHO}+$ $\mathrm{HCOOH}+\mathrm{BrCH}_{2} \mathrm{COOH}+6 \mathrm{H}^{+}$

In order to understand the mechanism of the inhibitory effect of hydrogen peroxide on the diacetone- $\mathrm{BrO}_{3}^{-}-\mathrm{Mn}(\mathrm{II})-\mathrm{H}_{2} \mathrm{SO}_{4}$ oscillating chemical reaction, the cyclic voltammetry was applied to monitor this system. Figure 4 shows the cyclic voltammograms of this system without potassium bromate (Fig. 


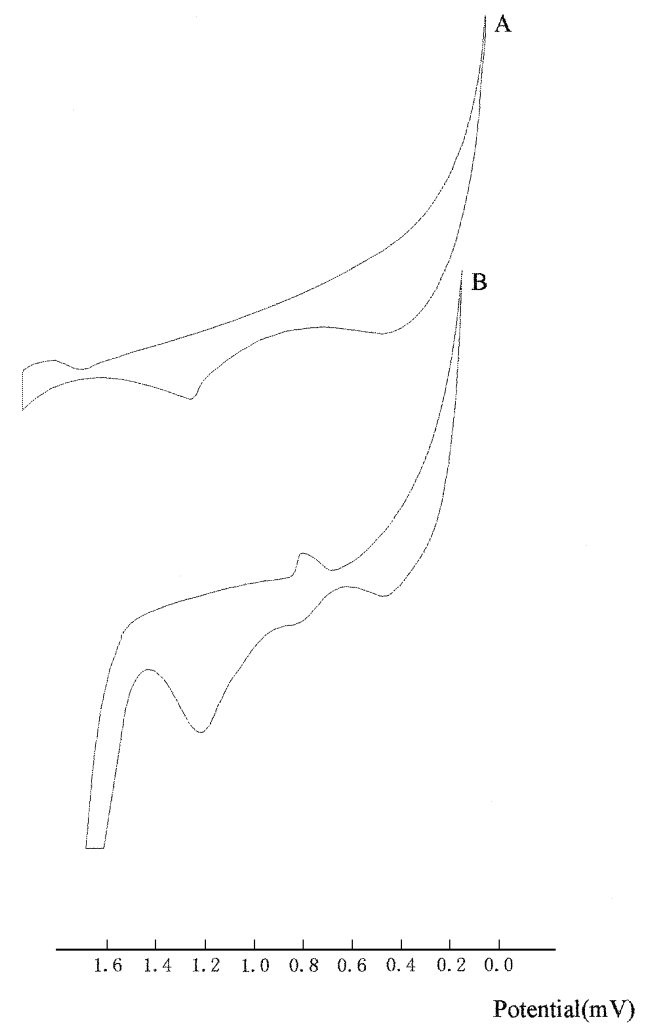

Fig. 4 Cyclic voltammograms of the system. (A) $\left[\mathrm{KBrO}_{3}\right]_{0}=0$, (B) $\left[\mathrm{KBrO}_{3}\right]_{0}=0.15 \mathrm{~mol} \mathrm{~L}^{-1}$. Common conditions: temperature 303 $\mathrm{K}$; scan rate, $1000 \mathrm{mV} \mathrm{s}^{-1}$; working electrode, glassy carbon electrode; diameter, $2 \mathrm{~mm}$.

4A) and with potassium bromate (Fig. 4B). The results indicate that when potassium bromate is added to the system, the system has a reversible couple (Fig. 4B). Peaks $\mathrm{P}_{\mathrm{c}}(+0.87 \mathrm{~V})$ and Peaks $\mathrm{P}_{\mathrm{a}}(+0.80 \mathrm{~V})$ correspond to the reversible $\mathrm{Br}_{2} / \mathrm{Br}^{-}$couple in the sulfuric acid solution. To clarify which species in the oscillating system reacts with hydrogen peroxide, different concentration of hydrogen peroxide are added, and the cyclic voltammogram of the system cavses obvious changes (Fig. 5). When different concentrations of hydrogen peroxide are added to the solution, these peaks disappear gradually (Fig. 5B, C). The results indicate that different concentrations of hydrogen peroxide have different effects on the reversible couple. In addition, when hydrogen peroxide is added to the solution, the oscillatory period increased immediately, and the yellow color deepened immediately, and eventually the solution became almost colorless, which means hydrogen peroxide inhibits the oscillating. So we propose hydrogen peroxide may affect the second path of the reaction.

$$
\mathrm{H}_{2} \mathrm{O}_{2}+2 \mathrm{Br}^{-}+2 \mathrm{H}^{+} \rightarrow \mathrm{Br}_{2}+2 \mathrm{H}_{2} \mathrm{O}
$$

It is the path in which much $\mathrm{Br}^{-}$is expended, the concentration of $\mathrm{Br}_{2}$ increases quickly. $\mathrm{Br}_{2}$ dominates the reaction (II), so the oscillatory period increased immediately. The other reaction paths have been affected only a little.

\section{References}

1. L. D. Bowers, Anal. Chem., 1996, 58, 513A.

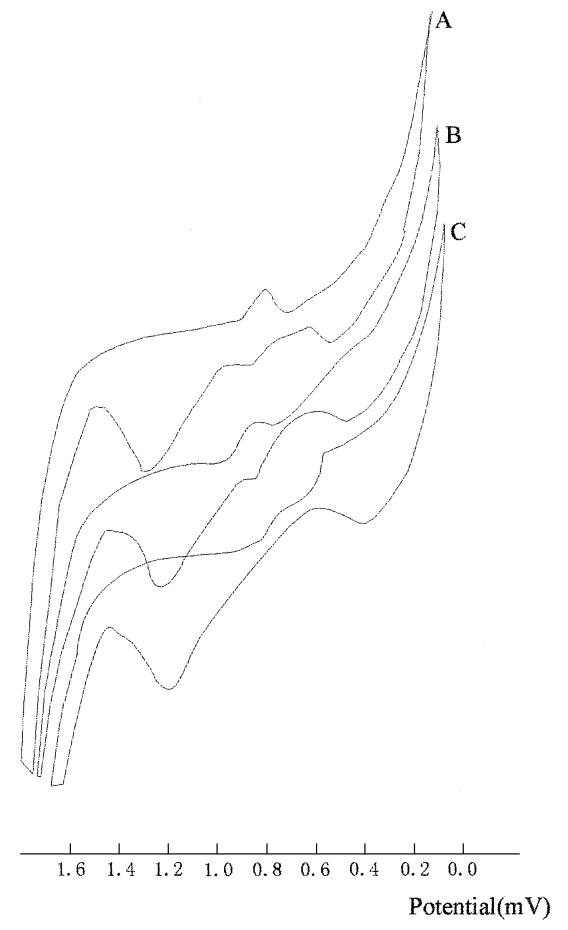

Fig. 5 Cyclic voltammograms of the system at concentrations of hydrogen peroxide of (A) 0 ; (B) $1.15 \times 10^{-6} \mathrm{~mol} \mathrm{~L}^{-1}$; (C) $7.05 \times 10^{-5}$ mol L ${ }^{-1}$. Other conditions as in Fig. 4 .

2. Q. Z. Zhu, Q. G. Li, J. Z. Lu, and J. G. Xu, Anal. Lett., 1996, 29, 1729.

3. B. J. Finlayson-Pitts and J. N. Pitts, "Atmospheric Chemistry: Fundamentals and Atmospheric Techniques", 1986, Wiley, New York, 668.

4. P. A. Tanner and A. Y. S. Wong, Anal. Chim. Acta, 1998, $370,279$.

5. A. I. Vigel, "Textbook of quantitative chemical analysis", 1989, Longman, London, 372.

6. C. Matsubara, N. Kawamoto, and K. Takamura, Analyst [Cambridge], 1992, 117, 1781.

7. U. Wollenberger, J. Wang, M. Ozsoz, E. GonzalezRomero, and F. Scheller, Bioelectrochem. Bioenerg., 1991, 26, 187.

8. M. Vreeke, R. Maidan, and A. Heller, Anal. Chem., 1992, 64, 3083.

9. J. Wang, B. Frieha, N. Naser, and E. Romero, Anal. Chim. Acta, 1991, 254, 81.

10. R. J. Field, J. Chem. Educ., 1972, 49, 308.

11. R. J. Field and F. W. Schneider, J. Chem. Educ., 1989, 66, 195.

12. R. J. Field and R. M. Noyes, J. Chem. Phys., 1974, 60, 1877.

13. M. Alamgir and I. R. Epstein, J. Am. Chem. Soc., 1983, 105, 2500.

14. R. Jimenez-Prieto, M. Silva, and D. Perez-Bendito, Talanta, 1997, 44, 6 and 1463.

15. R. Jimenez-Prieto, M. Silva, and D. Perez-Bendito, Analyst, 1997, 122, 287.

16. R. Jimenez-Prieto, M. Silva, and D. Perez-Bendito, Anal. Chem., 1995, 67, 729.

17. C. An, N. Gan, and R. Cai, J. Wuhan University (Natural Science Edition), 1999, 45IV, 411. 